\title{
Restless legs syndrome during and after pregnancy and its relation to snoring
}

\author{
Maria Sarberg, Ann Josefsson, Ann-Britt Wiréhn and Eva Svanborg
}

\section{Linköping University Post Print}

N.B.: When citing this work, cite the original article.

This is the authors' version of the following article:

Maria Sarberg, Ann Josefsson, Ann-Britt Wiréhn and Eva Svanborg, Restless legs syndrome during and after pregnancy and its relation to snoring, 2012, Acta Obstetricia et Gynecologica Scandinavica, (91), 7, 850-855.

which has been published in final form at:

http://dx.doi.org/10.1111/j.1600-0412.2012.01404.x

Copyright: Informa Healthcare / Wiley-Blackwell

http://eu.wiley.com/WileyCDA/Brand/id-35.html

Postprint available at: Linköping University Electronic Press

http://urn.kb.se/resolve?urn=urn:nbn:se:liu:diva-79784 


\section{Restless legs syndrome during and after pregnancy and its}

\section{relation to snoring}

Maria Sarberg, $\mathrm{MD}^{1}$, Ann Josefsson, $\mathrm{MD}, \mathrm{PhD}^{1}$, Ann-Britt Wiréhn, $\mathrm{PhD}^{2}$, Eva Svanborg, $\mathrm{MD}, \mathrm{PhD}^{3}$

${ }^{1}$ Division of Obstetrics and Gynecology, Department of Clinical and Experimental Medicine, Faculty of Health Sciences, Linköping University, Department of Obstetrics and Gynecology in Linköping, County Council of Östergötland, Linköping, Sweden

${ }^{2}$ Local Health Care Research and Development Unit, Faculty of Health Sciences, Linköping University, County Council of Östergötland, Linköping, Sweden

${ }^{3}$ Department of Clinical Neurophysiology, Faculty of Health Sciences, Linköping University, County Council of Östergötland, Linköping, Sweden

Correspondence: Maria Sarberg

Department of Obstetrics and Gynecology

University Hospital

SE - 58185 Linköping, Sweden

Tel: +46 1010331 30; fax: +4613148156

e-mail: maria.sarberg@lio.se 


\section{ABSTRACT}

Objective. To study development of restless legs syndrome (RLS) during and after pregnancy, and whether RLS is related to snoring or other pregnancyrelated symptoms.

Design. Prospective study.

Setting. Antenatal care clinics in the catchment area of Linköping university hospital, Sweden.

Population. Five hundred consecutively recruited pregnant women.

Methods. Sleep disturbances, including symptoms of restless legs syndrome and snoring was assessed with questionnaires in each trimester. A complementary questionnaire was sent three years after delivery to women experiencing RLS-symptoms during pregnancy.

Main outcome measures. RLS-symptoms in relation to snoring in each trimester.

Results. RLS-symptoms were reported by $17.0 \%$ of the women in the $1^{\text {st }}$, by $27.1 \%$ in the $2^{\text {nd }}$ and by $29.6 \%$ in the $3^{\text {rd }}$ trimester. Snoring in the $1^{\text {st }}$ trimester was correlated to increased prevalence of RLS in all three trimesters $(p=0.003$, 0.017 and 0.044$)$. No correlation was found between RLS and anemia, parity or body mass index. Among the RLS women $31 \%$ still had symptoms three years after delivery. Fifty-eight percent of those whose symptoms had disappeared stated that this happened within one month after delivery.

Conclusions. RLS-symptoms progressed most between the $1^{\text {st }}$ and $2^{\text {nd }}$ trimester. Women who snored in the $1^{\text {st }}$ or $2^{\text {nd }}$ trimester of pregnancy had a higher prevalence of RLS in the third trimester which indicates that snoring in 
early pregnancy might predict RLS later. Symptoms of RLS disappear quite soon after delivery, but about one-third of women with RLS during pregnancy may still have symptoms three years after childbirth. 


\section{KEYWORDS}

Restless legs syndrome (RLS), pregnancy, snoring, sleep, sleep disturbance

\section{ABBREVIATIONS}

$R L S$, restless legs syndrome; BMI, body mass index; ANC, antenatal care clinic

\section{CONFLICT OF INTEREST}

The authors have stated explicitly that there are no conflicts of interest in connection with the article. 


\section{INTRODUCTION}

During a normal pregnancy a wide range of different conditions and symptoms may occur. Impaired quality of sleep is common, and may be due to frequent nocturnal awakening, fewer hours of sleep and lower sleep efficacy $(1,2)$. Two factors known to affect sleep quality and to increase as the pregnancy proceeds are restless legs syndrome and snoring. Restless legs syndrome (RLS) is characterized as paresthesia or dysethesia, usually in the legs, causing a desire to move the limbs with immediate temporary relief by activity. The symptoms are aggravated at rest and in the evening or early night (3). Pregnancy is a risk factor for developing RLS, although the exact mechanisms behind this remain unclear. According to a review article from 2006 (4) the prevalence is $19-26 \%$ among pregnant women compared to $11 \%$ in Swedish women aged 25-34 years in the general population (5). RLS is most common during the last trimester, but its development during pregnancy has not been fully analyzed. Earlier studies of RLS among pregnant women have focused on prevalence (69) and effects of the quality of sleep $(1,10)$. Most of these studies are retrospective or cross-sectional $(7,9-12)$. To our knowledge there is no large prospective study focusing on the development of RLS during pregnancy. There are some surveys describing the development of RLS after delivery (1, $6-9,13,14)$, but of these only one (14) investigated the prevalence more than six months after childbirth.

The primary aim of this survey was to conduct a prospective study on RLS during pregnancy and its long-term persistence. Our secondary aim was to 
Restless legs syndrome and pregnancy

investigate whether RLS is related to the occurrence of snoring or other pregnancy-related symptoms. 


\section{MATERIAL AND METHODS}

The Swedish antenatal health care system reaches almost $100 \%$ of all pregnant women, free of charge. At the antenatal care clinics (ANC) healthy pregnant women are advised to attend the regular antenatal program with seven to nine visits to a midwife, and, if needed, extra appointments with an obstetrician and/or the midwife. The first visit generally takes place around gestational week $10-12(15)$.

Pregnant women consecutively registered at one ANC between March 2006 and March 2007 were asked to contribute to the study. Women with diabetes mellitus, neurological disease, drug abuse, hypertension or poor knowledge of the Swedish language at the first visit were excluded. After written and oral information 500 women agreed to participate in the study. A written informed consent was obtained from each participant. The women were presented a questionnaire, described below, at three regular visits to the $\mathrm{ANC}$ in the $1^{\text {st }}, 2^{\text {nd }}$ and $3^{\text {rd }}$ trimester. At the same visit body weight, blood pressure and hemoglobin level were recorded.

In the questionnaire the women were asked to answer the four separate questions set by the International RLS Study Group for diagnosing RLS (3):

1) Have you experienced unpleasant sensations in your legs combined with need for movement?

2) Are these sensations chiefly present when you are resting and is there improvement when you move? 
3) Are the sensations worse in the evenings or during the nights compared to the mornings?

4) How often do you have these sensations?

The women were also asked to rate the frequency of snoring, witnessed apnea, daytime sleepiness, daytime fatigue, edema in legs, feet or hands. They rated the frequency in terms of always, often, sometimes, seldom and never. The women were also given the Epworth Sleepiness Scale (16), a validated instrument for measuring excessive daytime sleepiness, where the person is asked to rate his or her probability of falling asleep on a scale of increasing probability from 0 to 3 for eight different situations.

Women who answered positively to the first three RLS questions in the questionnaire were considered sufferers from the syndrome if they had these symptoms at least once per month.

Data concerning characteristics of the women and their pregnancies (age, height, parity, iron and folate intake during pregnancy, weeks of pregnancy at delivery) and their newborn (sex, weight, Apgar score), were taken from the Swedish standardized antenatal and delivery records. In calculations concerning data taken from the medical records all 500 women were included. In statistics concerning development of symptoms during pregnancy, taken from the questionnaires, only the women who had completed all three questionnaires were included. 
All women who reported symptoms of RLS during their pregnancy were sent an additional questionnaire three years after childbirth. The follow-up questionnaire enquired if they still suffered from RLS symptoms and, if not, when the symptoms had disappeared.

Characteristics of the pregnant women were presented as mean and standard deviation (SD) for continuous variables and as numbers and proportions for discrete variables. The Z-test, with p-values, Bonferroni corrected for multiple comparisons, was used to evaluate differences in prevalence of RLS between the three trimesters. Differences between the proportions among women with and without experienced RLS concerning the severity trend of snoring (from never/seldom to always), were tested with the chi-squared trend test.

Differences between not reporting RLS and reporting RLS in at least one of the three questionnaires, was tested with t-test for continuous variables (age, weight gain, body mass index, hemoglobin level and Epworth sleepiness scale) and binary variables (sex of child, anemia) and with Pearson's chi-squared test for proportions in ordinal scaled variables from never/seldom to always (sleepiness and fatigue). The significance level was set to $5 \%$ in all tests. The statistical software SPSS 15.0 was used.

The study was approved by the Human Research Ethics Committee, Faculty of Health Sciences, Linköping University. 


\section{RESULTS}

In total 500 women answered the questionnaire in the $1^{\text {st }}$ trimester, 375 in the $2^{\text {nd }}$ and 351 in the $3^{\text {rd }}$ trimester. All three questionnaires were completed by 285 women. Eleven women had a miscarriage or abortion between the first and second occasion, 12 had preterm labor before the third occasion and nine moved to another city during their pregnancy. In the remaining 117 cases the cause of drop-out was unknown.

The women in the study had a mean age of 30.1 years at start of pregnancy and their characteristics corresponded to those of average Swedish pregnant women (15) (Table 1).

The frequency of experienced RLS was $17.0 \%$ in the $1^{\text {st }}$ trimester, $27.1 \%$ in the $2^{\text {nd }}$ and $29.6 \%$ in the $3^{\text {rd }}$ trimester (Figure 1 ). The difference in prevalence was significant ( $\mathrm{p}=0.003$ ) between the first and second, but not between the second and third trimester of pregnancy. Thirty-two percent of the women reported RLS at some stage of pregnancy. The frequency of snoring in the entire material rose from $7.7 \%$ women snoring "often" or "always" in the $1^{\text {st }}$ trimester to $18.9 \%$ in the $3^{\text {rd }}$ trimester of pregnancy.

Of the women suffering from RLS in the $1^{\text {st }}$ trimester $13.1 \%$ were snoring often or always, $19.6 \%$ of the women with RLS were snorers in the $2^{\text {nd }}$ trimester and $19.4 \%$ in the $3^{\text {rd }}$ trimester (Table 2). The chi-squared test for trend showed that snoring in $1^{\text {st }}$ trimester was correlated to increased 
prevalence of RLS in all three trimesters $(\mathrm{p}=0.003,0.017$ and 0.044 , respectively). Similar relations were found between snoring in $2^{\text {nd }}$ trimester and RLS in $2^{\text {nd }}$ and $3^{\text {rd }}$ trimester $(\mathrm{p}=0.04$ and 0.046$)$. There was no significant relation between snoring in $3^{\text {rd }}$ trimester and RLS in $3^{\text {rd }}$ trimester.

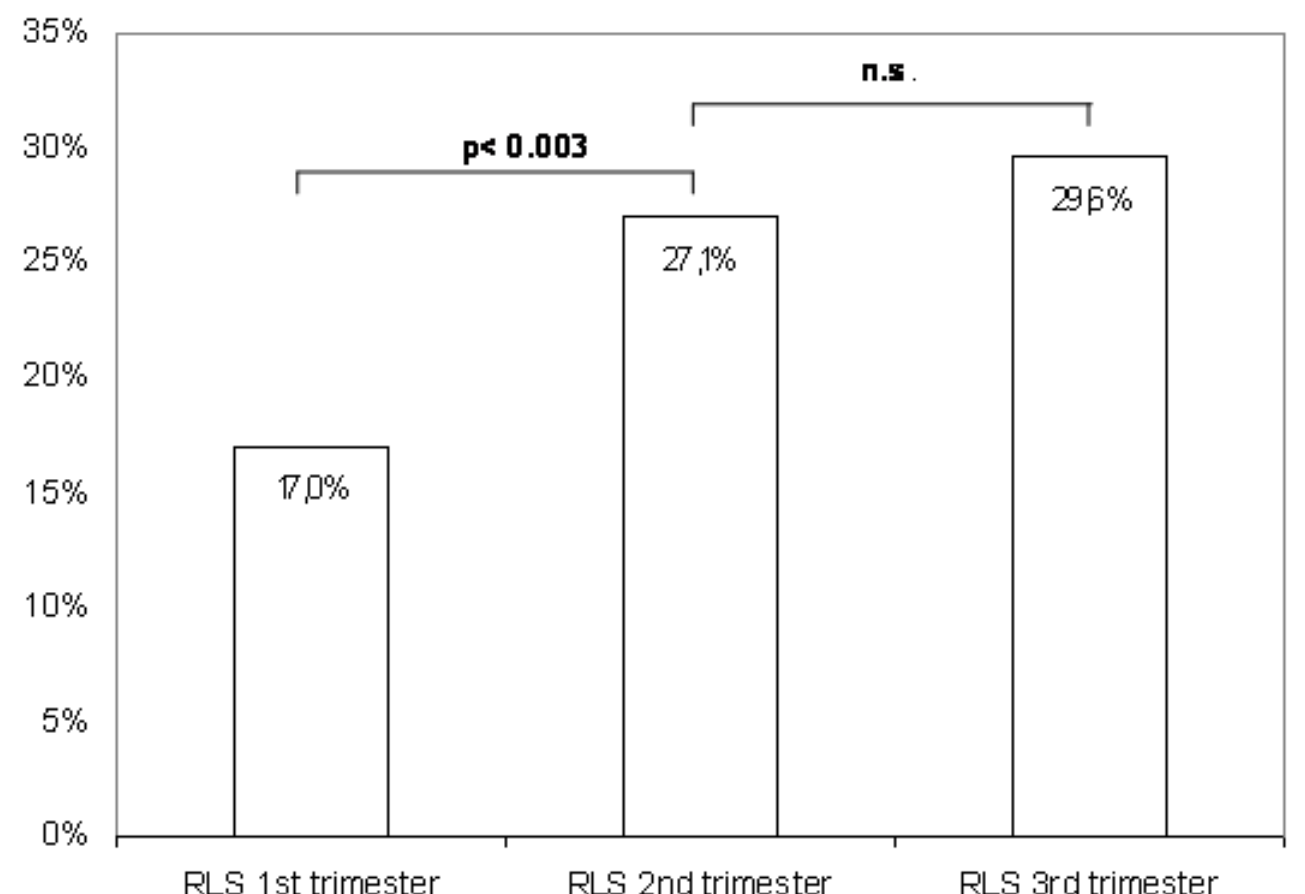

Figure 1. Prevalence of RLS in each trimester of pregnancy

There was no difference in age, parity, BMI or BMI-classes, weight gain during pregnancy, prevalence of anemia, hemoglobin level at start of pregnancy, intake of supplementary iron or folate, prevalence of edema or prevalence of twin pregnancy between RLS and non-RLS women. The women who fulfilled the criteria for RLS at any time during pregnancy experienced a greater amount of fatigue during $1^{\text {st }}(\mathrm{p}=0.001)$ and $3^{\text {rd }}$ trimester $(\mathrm{p}=0.003)$ and were more sleepy in all trimesters $(\mathrm{p}=0.045 ; 0.024$ and $<0.001)$ compared to 
women who did not suffer from RLS. Women with RLS scored higher on Epworth Sleepiness scale in $3^{\text {rd }}$ trimester $(\mathrm{p}=0.008)$, but not in the $1^{\text {st }}$ or $2^{\text {nd }}$ trimester. Women with RLS gave more often birth to female babies ( $\mathrm{p}=0.031)$.

All women who reported RLS-symptoms $(\mathrm{n}=160)$ were sent an additional questionnaire three years after childbirth and 109 (68.1\%) replied. Among those, 34 women $(31.2 \%)$ still suffered from RLS (five were pregnant again at follow-up). Among the 75 women who no longer suffered from RLS, 43 $(57.3 \%)$ did state that the symptoms had disappeared directly or within one month after delivery, $11(14.7 \%)$ had the problems during more than one month after delivery and $16(21.3 \%)$ did not remember when it disappeared. There was no difference in parity among the women who still suffered from RLS and the women who had recovered from the symptoms after delivery, neither between the ones with persisting symptoms and all others. 


\section{DISCUSSION}

We found an increase in prevalence of RLS during pregnancy, with the largest increase between the $1^{\text {st }}$ and $2^{\text {nd }}$ trimester of pregnancy. Snoring in early pregnancy was positively correlated to RLS later in pregnancy, indicating that snoring may predict the development of RLS. Three years after delivery onethird of the women still experienced the inconvenience of RLS symptoms.

To our knowledge, this is the first large, prospective study focusing on the development of RLS during pregnancy. Since almost all pregnant women in Sweden accept the antenatal heath care program the risk of selection bias was low. The criteria for RLS stated by the International RLS Study group (3) were used in the first three questionnaires, but not strictly in the follow-up. The prevalence of RLS in the study group before pregnancy is not known which might be a limitation, but the prevalence in the Swedish general population of that age group is estimated to be $11 \%$ (5). We did not perform any blood analyses except from the routine hemoglobin blood samples taken from pregnant women at the time of the study, implying that no analyzes of serum ferritin levels, serum folate or sex hormones were done.

The prevalence of RLS during pregnancy found in this study corresponds well with previous studies (1, 6-12). Previous studies describe an increased appearance and worsening of RLS-symptoms in the last trimester of pregnancy $(1,10-12,17)$, whereas our data indicated an earlier onset of symptoms and an unchanged occurrence between the $2^{\text {nd }}$ and $3^{\text {rd }}$ trimester of pregnancy. To 
some account this might be explained by our frequently distributed questionnaires, but even in studies where women answered questions in all three trimesters $(1,17)$ this pattern has not been described. However, in none of these two studies the criteria set by the International RLS Study Group for diagnosing RLS were used.

It is well known that pregnancy increases the prevalence of snoring $(18,19)$. However, a relation between snoring and RLS in pregnant women has, as far as we know, not earlier been investigated. One large multinational European study described an association between subjective loud snoring and RLS in the general population (both genders) and also defined diagnosed obstructive sleep apnea syndrome, a sleep disorder often manifested through snoring, as a strong predictor of RLS (20).

The relatively high rate of remaining RLS three years after childbirth in the present study differs from other studies which imply that the prevalence returns to pre-pregnant levels within 1-6 months after delivery $(1,6-9,12)$. The fact that one-third of the women with RLS during pregnancy still suffered from these symptoms after three years is therefore somewhat surprising. However, a similar result is described in a long-term follow-up study by Cesnik, where the prevalence of RLS in 74 women who experienced RLS during their pregnancy was $24.3 \% 6.5$ years after their delivery (14). This, in turn, could indicate that development of RLS during pregnancy is a risk factor for permanent, life-long disease, which correlates with a German study by Berger et al that identified 
pregnancy as one of the most important causes for the difference in prevalence of RLS between men and women (21). These results are also confirmed by two later studies of women with a family history of RLS, showing that familial RLS has more prominent symptoms among women with a higher number of pregnancies (22) and even indicated that the pregnancy risk factor might be limited to women with a family history of RLS (23).

There is no absolute explanation for the mechanisms of RLS development during pregnancy. In general, three interrelated components are thought to cause RLS: dopaminergic dysfunction, impaired iron homeostasis and genetic predisposition (24-26). In pregnant women there are studies indicating that low serum hemoglobin $(27,28)$, low folate levels $(17)$, less intake of supplementary iron (27) or high estradiol levels (13) are connected with the high prevalence of RLS. We found no correlation between low serum hemoglobin or intake of supplementary iron and RLS during pregnancy. The use of tobacco might be connected to an increased prevalence of RLS in a non pregnant population (4), but since relatively few Swedish pregnant women (7\%) state that they use tobacco during pregnancy (15) this was not investigated further in this material. A connection between alcohol use and RLS is also sometimes described, but the stated alcohol use during pregnancy is even lower.

The increased prevalence of snoring during pregnancy is thought to be due to diffuse pharyngeal edema leading to increased upper airway resistance (18, 29). It is not likely that the correlation between snoring and RLS was caused by 
concomitantly increased edema of the legs since we did not find any connection between peripheral edema and RLS in our material. A more likely explanation is that snoring decreases the quality of sleep, which might, in turn, increase the pregnant women's susceptibility for RLS symptoms. This is also in line with our findings that the pregnant women with RLS experienced a greater amount of fatigue and sleepiness than the women who did not suffer from RLS.

In conclusion, RLS is a common problem among pregnant women. It is important that midwives and doctors who meet these women recognize the symptoms and are able to explain both the symptoms and the expected development after delivery. More than one-third of the women who experience RLS during their pregnancy can expect to recover from the symptoms directly after giving birth and another third recovers within the following months, but the last third may develop a chronic condition, for which there is, however, efficient medication, especially after pregnancy. Medical staff should also be aware that snoring early in pregnancy appears to predict RLS.

\section{ACKNOWLEDGEMENTS}

This investigation was supported by grants from the County Council of Östergötland, Sweden. 


\section{REFERENCES}

1. Hedman C, Pohjasvaara T, TolonenU, Suhonen-Malm AS, Myllylä VV. Effects on pregnancy on mothers' sleep. Sleep Med 2002;3;37-42

2. Santiago JR, Nolledo MS, Kinzler W, Santiago TV. Sleep and sleep disorders in pregnancy. Ann Intern Med 2001;134;396-408

3. Walters AS. Toward a better definition of the restless legs syndrome. The international restless legs syndrome study group. Mov Disord $1995 ; 10(5) ; 634-642$

4. Garcia-Borreguero D, Egatz R, Winkelmann J, Berger K. Epidemiology of restless legs syndrome: The current status. Sleep Med Rev $2006 ; 10 ; 153-167$

5. Wesström J, Nilsson S, Sundström-Poromaa I, Ulfberg J. Restless legs syndrome among women: prevalence, co-morbidity and possible relationship to menopause. Climateric 2008;11;422-428

6. Goodman JDS, Brodie C, Ayida GA. Restless legs syndrome in pregnancy. BMJ 1988;297;1101-1102

7. Manconi M, Govoni V, De Vito A, Economou NT, Cesnik E, Casetta I, et al. Restless legs syndrome and pregnancy. Neurology 2004;63;10651069

8. Neau JP, Marion P, Mathis S, Julian A, Godeneche G, Larrieu D, et al. Restless legs syndrome and pregnancy: follow-up of pregnant women before and after delivery. Eur Neurol 2010;64;361-366 
9. Uglane MT, Westad S, Backe B. Restless legs syndrome during pregnancy is a frequent disorder with a good prognosis. Acta Obstet Gynecol Scand. 2011;90(9);1046-1048

10. Facco FL, Kramer J, Ho KH, Zee PC, Grabman WA. Sleep disturbances in pregnancy. Obst Gynecol 2010; 115(1); 77-83

11. Suzuki K, Ohida T, Sone T, Takemura S, Yokoyama E, Miyake T, et al. The prevalence of restless legs syndrome among pregnant women in Japan and the relationship between restless legs and sleep problems. Sleep 2003; 26(6);673-677

12. Alves DA, Carvalho LB, Morais JF, Prado GF. Restless legs syndrome during pregnancy in Brazilian women. Sleep Med 2010;11;1049-1054

13. Dzaja A, Wehrle R, Lancel M, Pollmächer T. Elevated estradiol plasma levels in women with restless legs during pregnancy. Sleep 2009;32(2);169-174

14. Cesnik E, Casetta I, Turri M, Govoni V, Granieri E, Ferini Strambi L, et al. Transient RLS during pregnancy is a risk factor for the chronic idiopathic form. Neurology 2010;75;2117-2120

15. Official Statistics of Sweden. Statistics - Health and medical care, pregnancies, deliveries and newborn infants. The Swedish medical birth registers 1973-2009. ISSN 1400-3511, ISBN 978-91-86585-93-8; 2011.

16. Johns MW. A new method of measuring daytime sleepiness: the Epworth sleepiness scale. Sleep 1991;14(6);540-545 
17. Lee KA, Zaffke ME, Baratte-Beebe K. Restless legs syndrome and sleep disturbance during pregnancy: The role of folate and iron. $\mathrm{J}$ Womens Health Gend Based Med 2001;10(4);335-341

18. Loube DI, Poceta JS, Morales MC, Peacock MD, Mitler MM. Selfreported snoring in pregnancy: association with fetal outcome. Chest $1996 ; 109 ; 885-889$

19. Venkata C, Saiprakash B, Venkateshiah B. Sleep-disordered breathing during pregnancy. J Am Board Fam Med 2009;22;158-168

20. Ohayon MM, Roth T. Prevalence of restless legs syndrome and periodic limb movement disorder in a general population. J Psychosom Res 2002;53;547-554

21. Berger K, Luedemann J, Trenkwalder C, John U, Kessler C. Sex and the risk of restless legs syndrome in general population. Arch Intern Med 2004;164;196-202

22. Xiong L, Montplaisir J, Desautels A, Barhdadi A, Turecki G, Levchenko A, et al. Family study of restless legs syndrome in Quebec, Canada. Arch Neurol 2010;67(5)617-622

23. Pantaleo NP, Hening WA, Allen RP, Earley CJ. Pregnancy accounts for most of the gender difference in prevalence of familial RLS. Sleep Med $2010 ; 11 ; 310-313$

24. Winkelman JW. Considering the causes of RLS. Eur J Neurol 2006;13(suppl3);8-14

25. Trenkwalder C, Paulus W, Walters AS. The restless legs syndrome. Lancet Neurol 2005;4;465-475 
26. Allen RP. Controversies and challenges in defining the etiology and pathophysiology of restless legs syndrome. Am J Med 2007; 120(1A),S13-21

27. Tunç T, Karadağ YS, Doğulu F, Ǐnan LE. Predisposing factors of restless legs syndrome in pregnancy. Mov Disord 2007;22(5);627-631

28. Sikandar R, Khealani BA, Wasay M. Predictors of restless legs syndrome in pregnancy: a hospital based cross sectional survey from Pakistan. Sleep Med 2009;10;676-678

29. Holdcroft A, Bevan DR, O’Sullivan EF, Sykes MK. Airway closure in pregnancy. Anesthesia 1977;32;517-523 
Table 1. Characteristics for the studied pregnant women

\begin{tabular}{|c|c|c|c|}
\hline & $\mathrm{n} \quad(\%)$ & Mean & (SD) \\
\hline Age $^{*}$ & & 30,1 & 4,5 \\
\hline Weight* & & 68,2 & 12,3 \\
\hline $\mathrm{BMI}^{*}$ & & 24,2 & 4,1 \\
\hline \multicolumn{4}{|l|}{ Parity } \\
\hline 0 & $232(46,4)$ & & \\
\hline 1 & $194(38,8)$ & & \\
\hline 2 & $61(12,2)$ & & \\
\hline$>2$ & $13 \quad(2,6)$ & & \\
\hline Weight gain (kg) & & 10,8 & 4,1 \\
\hline Fetal gender (male) & $239(49,6)$ & & \\
\hline Delivery week & & 39,2 & 2,1 \\
\hline Birth weight (g) & & 3504 & 571 \\
\hline Iron therapy ${ }^{\#}$ & $360(72,0)$ & & \\
\hline Folate therapy & $142(28,4)$ & & \\
\hline Hemoglobin† & & 130,8 & 9,4 \\
\hline RLS† (yes) & $160(32,0)$ & & \\
\hline
\end{tabular}

${ }^{*}$ at start of the pregnancy

\# $>6$ weeks anytime during pregnancy, Folate $\geq 250 \mu \mathrm{g} /$ day, Iron $\geq 50 \mathrm{mg} /$ day

† anytime during pregnancy 
Table 2. Cross-tabulation of pregnant women's experienced Restless legs syndrome (RLS) and snoring for each trimester of pregnancy

\begin{tabular}{|c|c|c|c|c|c|c|c|c|c|c|}
\hline & & \multicolumn{3}{|c|}{ RLS 1st trimester } & \multicolumn{3}{|c|}{ RLS 2st trimester } & \multicolumn{3}{|c|}{ RLS 3st trimester } \\
\hline & & $\begin{array}{l}\text { no \% } \\
(n)\end{array}$ & $\begin{array}{c}\text { yes \% } \\
(n)\end{array}$ & $\begin{array}{c}P- \\
\text { value* }^{*}\end{array}$ & $\begin{array}{l}\text { no \% } \\
(n)\end{array}$ & $\begin{array}{c}\text { yes \% } \\
(n)\end{array}$ & $\begin{array}{c}P- \\
\text { value* }^{*}\end{array}$ & $\begin{array}{c}\text { no \% } \\
\text { (n) }\end{array}$ & $\begin{array}{c}\text { yes \% } \\
(n)\end{array}$ & $\begin{array}{c}P- \\
\text { value* }\end{array}$ \\
\hline \multirow{5}{*}{$\begin{array}{l}\text { Snoring } \\
\text { 1st trimester }\end{array}$} & never/ seldom & 72,0 & 54,8 & \multirow{5}{*}{0.003} & 74,8 & 63,6 & \multirow{5}{*}{0.017} & 71,4 & 62,7 & \multirow{5}{*}{0.044} \\
\hline & sometimes & 21,5 & 32,1 & & 20,0 & 24,2 & & 22,9 & 24,5 & \\
\hline & often & 4,9 & 10,7 & & 3,7 & 10,1 & & 3,7 & 9,8 & \\
\hline & always & 1,7 & 2,4 & & 1,5 & 2,0 & & 2,0 & 2,9 & \\
\hline & & $(410)$ & (84) & & $(270)$ & (99) & & (245) & (102) & \\
\hline \multirow{5}{*}{$\begin{array}{l}\text { Snoring } \\
\text { 2st trimester }\end{array}$} & never/ seldom & & & & 63,5 & 51,0 & \multirow{5}{*}{0.004} & 62,8 & 53,4 & \multirow{5}{*}{0.049} \\
\hline & sometimes & & & & 26,6 & 29,4 & & 28,6 & 30,7 & \\
\hline & often & & & & 7,4 & 11,8 & & 6,1 & 10,2 & \\
\hline & always & & & & 2,6 & 7,8 & & 2,6 & 5,7 & \\
\hline & & & & & $(271)$ & (102) & & (196) & (88) & \\
\hline \multirow{3}{*}{$\begin{array}{l}\text { Snoring } \\
\text { 3st trimester }\end{array}$} & never/ seldom & & & & & & & 56,6 & 49,5 & \multirow{3}{*}{0.301} \\
\hline & sometimes & & & & & & & 25,0 & 31,1 & \\
\hline & often & & & & & & & 15,2 & 13,6 & \\
\hline
\end{tabular}


Restless legs syndrome and pregnancy

always 5,8

* $=$ Chi-square test for trend 